\title{
Developing Statistical Optimization Models for Urban Competitiveness Index: Under the Boundaries of Econophysics Approach
}

\author{
Cem Çağrı Dönmez $\mathbb{D}^{1}$ and Abdulkadir Atalan $\mathbb{D}^{1,2}$ \\ ${ }^{1}$ Department of Industrial Engineering, Marmara University, Istanbul, Turkey \\ ${ }^{2}$ Department of Mechanical Engineering, Bayburt University, Bayburt, Turkey \\ Correspondence should be addressed to Cem Çağrı Dönmez; cem.donmez@marmara.edu.tr
}

Received 30 August 2019; Accepted 8 October 2019; Published 20 November 2019

Guest Editor: Marco Locurcio

Copyright (c) 2019 Cem Çağrı Dönmez and Abdulkadir Atalan. This is an open access article distributed under the Creative Commons Attribution License, which permits unrestricted use, distribution, and reproduction in any medium, provided the original work is properly cited.

\begin{abstract}
The purpose of this research was to establish the urban competitiveness index (UCI) by using the statistical optimization method for the econophysics approach. With this technique, economic data regarding urban areas and the factors affecting UCI have been determined. The research covers 30 urban centres located in 15 countries worldwide. Urban centres with the gross domestic product per capita of $\$ 10,000$ or more were taken into consideration. The significant levels of the factors were determined with the statistical optimization method, and optimum values were calculated with the developed optimization models. Re-index values were calculated and compared with the results of PricewaterhouseCoopers and World Economic Forum. According to the results, the high UCI value of these locations depends not only on economic data but also on high values of social factors. Thus, those locations are becoming the centre of attraction for investments and capital with increasing competitiveness.
\end{abstract}

\section{Introduction}

During the last forty years, new developments in the dynamics of the urban system in physics, the main incentive has come from mathematicians and physicists mainly adaptive cognitive systems in the economical perspective who started applying their models of emerging properties to engineering then to social sciences. which would give a global framework for explaining systems dynamics in a wide range of fields of knowledge [1]. Economic development research has been moving to data-driven approaches within the methodology of natural science, statistical physics, and complexity sciences [2-4], which makes it possible to introduce new metrics that surpass the traditional economic measures in revealing current economic status and predicting future economic growth, with applications to economic development [5, 6], trading behaviour [7], poverty $[8,9]$, inequality $[10,11]$, unemployment $[12,13]$, and industrial structure $[5,14]$. Economists and physicists have also introduced a variety of nonmonetary metrics to quantitatively assess the country's economic diversity and competitiveness by measuring intangible assets of the economic system $[15,16]$, allowing for quantifying the economies' hidden potential for future development $[17,18]$ in near real time and at low cost [19].

Many economic methods have been used for the analysis of urban economy problems. One of these methods is the econophysics approach. Econophysics was first introduced in India as a word, "Economics" and "Physics," a conference on statistical physics in $1995[20,21]$. "Econophysics" is a new discipline insufficiently rooted in economic theory and empirical observation. Another peculiarity of new complex system theory is to focus on the emergence of properties at a macrolevel resulting from the interactions between individual behaviour at a microlevel [1]. Although this term deals with the relations between economics, physics, mathematics, and finance, it basically takes into account the interaction of theories of physics with the economy [20]. This method, which is generally recommended for macroeconomics, is intended to be used for microstructures of 
financial markets. Moreover, it is seen that the econophysics method is widely used by the statistical method as a result of research studies because in the characteristic structures of economics data, financial time series leads to statistical features and empirical studies $[22,23]$. In this research, the econophysics method was used for statistical physics to address urban competitiveness. As a matter of fact, the data are measured locally rather than globally. Additionally, economists and physicists have applied network and statistical methods to reshape the understanding of international trade that the knowledge about exporting to a destination diffuses among related products and geographic neighbours [24]. More recent works on econophysics and complexity are summarized by review papers $[20,25,26]$ and books [20, 27].

The processes of economic, social, and political change constantly affect the economic balance in the urban centres and reveal the necessity of renewing and planning them in terms of competitiveness [28]. Not only national changes, but the fact that they have centres that can govern themselves, accelerate and shape this need The European Union (EU) is at the forefront, especially for the growing cities of developing countries to be at a competitive level. According to general belief, urban areas with less uncertainty and imbalance in the economy are more competitive than other cities [29-31]. This situation contributes to the rapid change and development of the urban. However, it is seen that the rapid changes of economic structures lead to uncertainty and imbalance in the economies of urban areas, and uncertainty and imbalance dominate in real economies [32]. Within this information, it is seen that the economic theories used are inadequate to account for sudden changes in the economy (fluctuations, sudden movements in the parts and mobility in the capital markets, etc.) [33]. The uncertainty and imbalance of the fluctuations in the economy have led to the emergence of new concepts and approaches. But, there is no specific model to reduce uncertainty and imbalance in the economy, and there are only temporarily developed models. The main reason for this is that the economic structures are complex and the change in the economy is fast. In such cases, the structures that form in the economies are transforming into stochastic models on a statistical basis [21]. In this work, we aimed to solve the problems of uncertainty and imbalance in the economy of urban areas by choosing the contemporary method of the optimization statistical physic techniques to reach the concept of econophysics.

Towards quantifying the complexity of a country's economy, the pioneering attempt was made by Hidalgo and Hausmann [16] who modelled the international trade flows as "Country-Product" networks and derived the Economic Complexity Index (ECI) by characterizing the network structure through a set of linear iterative equations, coupling the diversity of a country (the number of products exported by that country) and the ubiquity of a product (the number of countries exporting that product). The intuition behind this new branch of studies is that the cross-country income differences can be explained by differences in economic complexity, which is measured by the diversity of a country's "capabilities" [15, 16, 19]; the statistical properties of financial markets have begun to apply physics concepts economically by attracting physicists [34]. Econophysicists have tried to use the theoretical approach of physical statistics to understand empirical findings [35]. Generally, many methods known in statistical physics have been applied to characterize time evolution in stock prices and exchange rates [34]. In the first examination, econophysics can be seen as wide physics models in the economy, that is, more quantitative approach, statistical models, concepts, and calculation methods. The macroscopic properties of intrinsic microscopic interactions cause a complex system in the economy. At this point, econophysics is associated with physical complexity (complex structures), reducing uncertainty and imbalance in the economy [36]. Immediately after those studies described above, Tacchella and research colleagues [37] developed a new statistical approach which defines a country's fitness and a product's complexity by the fixed points of a set of nonlinear iterative equations [38], where the complexity of products is bounded by the fitness of the less competitive countries exporting them. Further, Cristelli and research colleagues [18] studied the heterogeneous dynamics of economic complexity and found, in the fitness-income plane, strong explanatory power of economic development in the laminar regime and weak explanatory power in the chaotic regime. Based on this observation, they argued that regressions are inappropriate in dealing with this heterogeneous scenario of economic development and further proposed a selective predictability scheme to predict the evolution of countries. Nevertheless, these economic complexity indicators are not perfect, for example, ECI suffers from criticisms on its self-consistency, fitness depends on the dimension of the phase space of the heterogeneous dynamics of economic complexity [17, 18], and a new variant of the fitness method, called minimal extremal metric, can perform even better for a noise-free dataset [39]. Recently, Mariani and research colleagues [40] quantitatively compared the ability of ECI and fitness in ranking countries and products and further investigated a generalization of the "Fitness-Complexity" metric.

In general, the uncertainty and imbalance in the economy have been considered to be reduced by the Gaussian law [41]. This approach is not enough to reduce uncertainty and imbalance in the economy. This law is suitable for the use in economically viable microscopic models, such as the principle of randomly proportional effect. However, with the application of microdimension models for the complex structure of economies, healthy results cannot be obtained. In another study, the econometric approach was taken as quantum statistics. In this work, entropy, temperature, free energy, and the Hamiltonian concepts in probability theory are integrated into the quantum statistical method for mathematical financing [42]. As a result, the uncertainty of the phase transitions in mathematical finance has been found to depend on the temperature of the distribution, although the precision of the mathematical financial data is not known due to the uncertainty of the phase change. In order to acquire a more tangible result in this statistical analysis, optimization models with statistical physics have been used to obtain information about the competitiveness 
of urban areas and their future competitiveness. Thus, it is inevitable to take the econophysics approach with physical statistics. The recent econophysical approach is that economic phenomena are related to statistical physics models [43].

Urban competitiveness structures are very difficult to delimitate. The trading networks are evolving through time. Furthermore, urban structures are open (the exchanges with their environment enable, for instance, the introduction of technical or social innovations) and are overlapping, as an articulation of interlocked networks [1]. Understanding how economies develop to prosperity and figuring out the best indicators that reveal the status of economic development are long-standing challenges in economics $[13,44]$, which have far-reaching implications to practical applications. Traditional macroeconomic indicators, like gross domestic product (GDP), are widely applied to reveal the status of economic development; however, calculating these economic census-based indicators is usually costly, resource consuming, and thus a long-time delay [45].

Other techniques have been used to create urban competitiveness index (UCI) besides the statistical physics method. The competitiveness index of four UK cities, Birmingham, Liverpool, Glasgow, and Belfast, was established using the Delphi method and analytic hierarchy process with the multicriteria analysis method. In order to assess the urban competitiveness with the method used, city competitiveness was recommended to be strengthened and renovated and synergies of business strategies were to be established [46]. In support of this work, the benefits of urban renewal and change have been discussed through the creation of new creative industries, corporations, and institutions in the cities [47]. Another study concerning midsized French cities is aimed at increasing the competitiveness of the cities with both the efficient use of metropolitan assets and the resources of the land of the cities [48]. One of the different approaches of the study of urban competitiveness has measured two factors for examining the urban competitiveness power of Malaysian cities which are the diminished cultural life aspects of the cities and the marginalized flights to the economic suburbs [49].

On the basis of the studies made for urban competitiveness, the most important factors affecting the urban economy are considered by the national economy. The reason behind this is that the current state of the global economy and capital constraints are increasing the competition between them by putting pressure on the cities of the world [50]. However, when urban competitiveness ties to the factors of the country's economy, it creates a gap in its competitiveness [51]. This is because the presence of new competitors and the variability of targets for cities are linked not only to the country's factors but also to the internal and external factors. For this reason, cities' competitiveness needs to be understood in terms of the strengths and weaknesses of the factors that affect their competitors. In order to establish the UCI, the econophysics approach has been used, considering the internal and external factors of the cities. The key contribution of this research is to compare the urban competitiveness of cities with how they are positively affecting the social lives of the people as well as how competitive the cities are in attracting investment and capital to them.

Urban competitiveness is structurally complex and multidimensional, and it differs depending on the variety of factors used in the developed methods [52]. Generally, the factors derived from Eurostat [53] are taken into consideration in such studies. However, in the work done, some restrictions were applied to the selected cities. For example, Sáez and Periáñez [50] studied that the population of selected cities was more than 100,000. Thus, differences in the number and type of factors used in studies can correlate with the methods used. The number of factors and cities used in the study varies from 1 to 199 [54-56]. The cities were studied with their per capita income which are thought to be influenced by urban competitiveness are 10,000 dollars and more are taken into consideration. The generated UCI is compared with the cities based on an artificial index.

The main focus of this research is a comparison of how competitive big cities are in terms of locating and attracting investment. Since urban competitiveness is a complex, multidimensional issue, it is aimed to develop the UCI by developing optimization statistical method for the econophysics approach. This work contributes to the literature in the field of countries growing complexity, and the UCI was first explored by the econophysics approach in this research.

This work consists of four main parts. In Section 1, a literature study was carried out by examining the econophysics theory and UCI. Section 2 underlines the importance of the factors and responses that constitute the UCI. Development of optimization models for UCI is discussed in this section. The results of optimization models by statistical analysis for UCI and interpretations of this study are handled in Section 3. Finally, Section 4 includes conclusions and future research.

\section{Methodology}

2.1. Urban Competitiveness Factors. Econophysics in urban economy has been defined as a new discipline by using statistical physics methods on urban competitiveness problems. In this case, urban economy with a complex structure can be understood with a new approach, the econophysics. The data obtained in the social, economic, and cultural fields constituting the urban economy have been interpreted by the econophysics approach. The results obtained by the econophysics methodology are used to evaluate the complexity of irregular forms, and nowadays, economists are able to apply them in the field of UC up to urban development models.

Urban economy is the biggest element that constitutes the macro economy of a country. In the structure of the region where the urban economy is located, work force, productivity, education etc., are directly connected to the factors. The stability of the UCI depends not only on these factors but also on the macroeconomic structure of the country where the economy is located. Cities, which are metropolises, also bring urban competitiveness as they have large economies. The strength of the economy of 
metropolitan cities depends on many elements. In particular, urban areas' commercial performance and productivity play an important role in urban competitiveness because of its contribution to the urban economy.

A number of methods have been developed for the measurement of UCI, and these methods have been used as an indicator system and weight unit and UCI in general. In the 2011-2012 Global Urban Competitiveness Report, a model of the UC output was created, focusing only on the economic parameters of cities [57]. The model is formulated accordingly, and the result is achieved. The economic size, efficiency, grade, quality, density, and effect of cities are taken into account in the form [58]. For the World Bank, there are four key factors in the evaluation report on the UC which were highlighted: economic structure, human resources, regional wealth, and factors of institutional structure. UCI was created by giving some values to these factors [59]. In order to calculate the urban competitiveness indices of the four cities of United Kingdom, investment, finance, social capital, improvement, and use/occupant's possible and physical environment factors were determined. These factors are regarded as operational components in that study. Calculated factor scores did not capture any city superiority, but some cities had the highest scores for certain factors [46].

In another research, nine different factors were considered fewer than three main headings to form the UCI. These factors are determined as transportation, health, basic education, economy activities, labor force, higher education, business sophistication, knowledge society, and information society of the cities [50]. As a result of the statistical analysis, it was understood that the outcome in the infrastructure, not in the singularities, belong to these factors. However, the inadequacies of this study are that the factors should be studied, not as a group but as an interaction and singularity. It can be concluded the factors must be studied individually and interactively before the group is formed. For example, the factor " $a$ " that affects the competence of urban competitiveness and the factor " $b$ " with little or no effect should be considered as singular, and they should be calculated as significant or insignificant as a result of interactions. Moreover, ignoring the elements of the economy from the factors that influence a city's competitive power triggers the inadequate results to be achieved. It is also said that a city's competitive power is inversely proportional to the economic development. However, this proposal does not find a scientific infrastructure. Basically, the fact that the economic activity factor is statistically significant among the factors cogitated means that the relationship between urban competitiveness and the urban economy is strong.

In this work, 38 indicators were mentioned under six main factors (see Table 1). The data employed in this research cover the years of 2016 and 2017 [53, 55, 60, 61]. It was designed to establish UCI by considering the factors that are expressed statistically significant in previous studies. The fact that there are different factors in one study suggests the existence a complex structure for UCI and not a linear one. Having said that it is possible to increase the numbers of these factors and indicators; the mathematical optimization
TABLE 1: Indicators of the affecting factors of UCI.

\begin{tabular}{|c|c|c|}
\hline Factors & Indicators & Notations \\
\hline $\begin{array}{l}\text { Education, health, and } \\
\text { training }\end{array}$ & $\begin{array}{c}\text { Education system } \\
\text { Higher education } \\
\text { Primary and secondary } \\
\text { level } \\
\text { Information and knowledge } \\
\text { society } \\
\text { Trained persons rate } \\
\text { Healthcare infrastructure } \\
\text { Health policies }\end{array}$ & ET \\
\hline Labor and transport & $\begin{array}{c}\text { Old person employment } \\
\text { rate } \\
\text { Young person employment } \\
\text { rate } \\
\text { Female employment rate } \\
\text { Unemployment rate } \\
\text { Transport infrastructure } \\
\text { Shipping transport variety }\end{array}$ & $\mathrm{LT}$ \\
\hline $\begin{array}{l}\text { Technology and } \\
\text { industry }\end{array}$ & $\begin{array}{l}\text { Industrial structures and } \\
\text { standard } \\
\text { Technology infrastructure } \\
\text { Technological development } \\
\text { Information technology } \\
\text { Production technology }\end{array}$ & TI \\
\hline Market size & $\begin{array}{l}\text { Company variety } \\
\text { Product variety } \\
\text { Market economy } \\
\text { Market growth rate } \\
\text { Sales cycles } \\
\text { Company earnings } \\
\end{array}$ & MS \\
\hline Product efficiency & $\begin{array}{c}\text { Product variety } \\
\text { Product quality } \\
\text { Product supply-demand } \\
\text { level } \\
\text { Production speed } \\
\text { Cost of products } \\
\text { Product consumption time } \\
\text { Easy-to-carry } \\
\text { Product type (portability) }\end{array}$ & $\mathrm{PE}$ \\
\hline Financial service & $\begin{array}{l}\text { Stability of financial system } \\
\text { Financial development } \\
\text { Bank index } \\
\text { Currency and credit } \\
\text { Investment convenience } \\
\text { Capital rate }\end{array}$ & FS \\
\hline
\end{tabular}

model can be obtained and applied to become more complex and stochastic. The analysis of this model will be very difficult and time consuming, resulting in having distance from optimum values. Statistical analysis is to be maintained by determining factors that are important to reduce this complexity and constitute many subunits as the target factor. Thus, in order to establish the UCI, the econophysics approach has been used by considering the internal and external factors of the cities. In this model, population, energy, and environmental factors were ignored. The study covers 30 cities located in 15 countries worldwide. In statistical analysis to be performed, for each factor, the gross domestic product per capita was used for 30 different cities over $\$ 10,000[60]$. 
2.2. Urban Competitiveness Response Variables. Variations in the economic, environmental, and social structures are evident in determining urban competitiveness factors. In this context, the urban competitiveness levels of the analyses in the scientific literature are still being modelled. From a researcher's point of view, a city can be artificially measured according to its competitive power using different methods and theoretical models. Advantages and disadvantages of each method for urban competitiveness are stated, and they consequently contribute to finding the most reliable system.

In this probe, a number of ways have been identified in determining the factors affecting urban competitiveness and the affected responses. Researchers working on urban competitiveness assume that factors are more directly influenced by the UCI value. When computing the UCI value, they referred to the values attributed to the factors and the formation of an artificial index. The indexes formed in some research are calculated according to the Nash theory and Freudenberg method. In such academic work, the relative weights of the indicators resulting from the weighting of the factors have been calculated. In other words, weighting calculations are made according to the weight of each indicator to obtain relative weights.

In another case study, UCI values were calculated by using a closed formulation method by giving a certain range of values to the factors and comparing the competitiveness of the cities. For example, in the global competitiveness report prepared by $\mathrm{Ni}$ in 2014, factors were evaluated between 1 and 7. Subsequently, the urban competitiveness latent formula consisting of six different factors was obtained [57]. In the competitiveness index developed for the 24 cities of Lithuania, the steps and basic characteristics of the composite index were used to measure urban competitiveness [62]. Similarly, the urban competitiveness forces of 23 US cities were measured by statistical analysis taking into account only 3 different factors [63].

When we measure the urban competitiveness in our perspective, it is thought that the factors indirectly affect the UCI value, not directly. The reason for this is that there are some responses that these factors influence. We think that UCI values will be formed in the direction of the results obtained from these responses. There are two main responses to this study. These are the gross domestic product (UGDP) and the gross domestic product per capita (UGDPPC) of the urban areas considered for the UCI. The reason for taking these responses into consideration is the competitiveness of the cities and the measurement of the cities by their economic growth. Some researchers have considered these responses as factors for the strength of urban competitiveness. They have even argued that the economic growth of cities and the strength of urban competitiveness are directly proportional $[64,65]$.

2.3. Development of Optimization Models for UCI. The areas of use of mathematical optimization models vary. In particular, these models are used to solve the problems that cost, and benefit dilemmas are taken into consideration.
Mathematical modelling is carried out with the aim of reducing the cost and maximizing the benefits. In this study, statistical analysis of the mathematical model was performed. There are three basic things that make up mathematical models. In a mathematical model, the objective function, constraints, and decision-variable signs are considered. There are three stages in the mathematical model created in this study. In the first step, the equations obtained as a result of statistical analysis are considered as objective functions. The next step is to obtain the data from the lower and upper limits that constitute the constraints. The fact that the index values used for the factors are greater than zero causes the decision variables to be greater than zero. In the optimization model developed for this study, the values of the decision variables will be greater than zero.

As a final step, the optimal values required for a city to have competitiveness have been calculated. A desirability function was developed to compute UCI scores of cities for the comparative outcome of the previous urban competitiveness index. Through these functions, comparisons of competitiveness of cities were made.

Attention should be paid to the desirability value when achieving optimum results. Before constructing the optimization models, it is necessary to consider the function of desirability according to the results to be obtained as a result of statistical analysis. The factors affecting the response function directly affect the desirability function [66]. In short, it is desirable that the factors affecting the main response values are at the desired values. This is measured by the value of desirability. The best result is obtained as this value goes from zero to one when calculating desirability.

To find $n$ factors' values, the function of each response value is expressed as

$$
y_{i}=f_{i}\left(x_{1}, x_{2}, \ldots, x_{k}\right), \quad i=1,2, \ldots, n .
$$

The desirability function is specified as

$$
d_{i}=d_{i}\left(y_{i}\right)=d_{i}\left(y_{i}(x)\right)
$$

where $d(y)$ takes a value between 0 and 1 . If $d_{i}\left(y_{i}\right)=1$, this is the desired best value $[67,68]$, but if $d_{i}\left(y_{i}\right)=0$, it is the worst and undesirable value.

General desirability is expressed as follows:

$$
d_{i}\left(y_{i}\right)=\left(\frac{y_{i}-l_{i}}{u_{i}-l_{i}}\right)^{w_{i}}, \quad l_{i} \leq y_{i} \leq u_{i},
$$

where $l_{i}$ and $u_{i}$ are the lower and upper specification limit of the responses, the power $w_{i}$ corresponds to the weighted factor, and $w_{i}$ is the parameter that determines the shape of $d_{i}\left(y_{i}\right)$. There are three purposes for the value of desirability. These are maximum, minimum, and target values in the objective function. In this study, formula (4) was considered in order to achieve maximum values of the objective functions. There are three different conditions for each of these three situations.

For maximization problems, the desirability functions are 


$$
d^{\max }= \begin{cases}0, & \text { if } y_{i} \leq l, \\ \left(\frac{y_{i}-l}{u-l}\right)^{w_{i}}, & \text { if } y_{i} \leq u, y_{i} \geq l \\ 1, & \text { if } y_{i} \geq u\end{cases}
$$

For minimization problems, the desirability function is

$$
d^{\min }= \begin{cases}0, & \text { if } y_{i} \geq u, \\ \left(\frac{u-y_{i}}{u-l}\right)^{w_{i}}, & \text { if } y_{i} \leq u, y_{i} \geq l \\ 1, & \text { if } y_{i} \leq l .\end{cases}
$$

For target, the desirability function is

$$
d^{\text {target }}= \begin{cases}\left(\frac{y_{i}-l}{u-l}\right)^{w_{i}}, & \text { if } y_{i} \leq u, y_{i} \geq l, \\ \left(\frac{u-y_{i}}{u-l}\right)^{w_{i}}, & \text { if } y_{i} \leq u, y_{i} \geq l, \\ 0, & \text { if } y_{i} \leq l \text { and } y_{i} \geq u .\end{cases}
$$

At the same time, for these three cases, nominal the best (NTB) for the target, smaller the better (STB) for the minimum, and larger the better (LTB) for the maximum conditions are defined in previous research studies [69]. The overall desirability function equation to be obtained by considering these three conditions is calculated by the geometric mean (see equation (7)). The use of the geometric mean is due to the fact that more than one dimensionless individual desirability scales arise. The individual desirability scales are merely a whole using a geometric mean and merges them into one desirability.

$$
d=\left(d_{1} * d_{2} * d_{3} * \ldots * d_{n}\right)^{1 / n}
$$

The overall desirability function includes the upper and lower bound values of the factors that have an effect on the response. UCI was created separately for each factor. UCI formula was obtained by geometric mean of these factors.
The parameters analyzed as a result of statistical analysis were global-based so as to construct the UCI:

$$
\mathrm{UCI}=\frac{\left[\left(c_{1}+\sum_{i=1}^{n} p_{i, k} r_{k}\right) \mathrm{UGDP}_{i}\right]}{c_{2}},
$$

and

$$
\mathrm{UCI}=\frac{\left[\left(c_{1}+\sum_{i=1}^{n} p_{i, k} r_{k}\right)(\mathrm{GDP} P C)_{i}\right]}{c_{2}}
$$

where UCI is the urban competitiveness index, $c_{1}$ is the regression constant, $c_{2}$ is the normalization constant, $p i$ and $k$ are competitiveness parameters, $r_{k}$ is the regression multiplier, $\mathrm{UDGP}_{i}$ is the gross domestic product of urban, and (UDGP PC) $)_{i}$ is the gross domestic product per capita of urban.

In this investigation, optimal UCI for each urban area needs to be established in order for cities to have competitive power. Contemplating two objective functions, it was aimed to maximize the urban competitiveness of cities. Both optimization models contain the same constraints. For the calculation of GDP belonging to the urban area (closed formula),

$$
\begin{array}{ll}
\underset{\text { maximize }}{\text { subject to }} & \mathrm{UGDP} i \\
& l \leq x_{j}, \\
& x_{j} \leq u, \\
& 0 \leq x_{j} .
\end{array}
$$

Optimization equation of the UGDP-PC (closed formula):

$$
\begin{array}{ll}
\text { maximize } & \mathrm{UGDP} P C i \\
\text { subject to } & \\
& l \leq x_{j}, \\
& x_{j} \leq u, \\
& 0 \leq x_{j} .
\end{array}
$$

With this objective function, the two response variables are reduced to a single form. Thus, whichever response is maximum is the optimum value for UCI. The optimization model that maximizes the urban competitiveness index is formulated as follows:

$$
\begin{aligned}
& \operatorname{maximize}_{\mathrm{UCI}}\left\{\sum_{y_{i}}^{y_{f}}\left[\frac{\left[\left(\left(c_{1}+\sum_{i=1}^{n} p_{i, k} r_{k}\right)\left(\mathrm{UDGP}_{i}\right)\right) /\left(c_{2}\right)\right]}{y_{f}-y_{i}}\right], \sum_{y_{i}}^{y_{f}}\left[\frac{\left.\left[\left(c_{1}+\sum_{i=1}^{n} p_{i, k} r_{k}\right)\left(\mathrm{UDGP} \mathrm{PC}_{i}\right) /\left(c_{2}\right)\right]\right]}{y_{f}-y_{i}}\right]\right\}, \\
& \text { subject to } \quad\left[\frac{\left(\sum_{y_{i}}^{y_{f}} \min \left\{l_{i j}^{y_{i}}, \ldots, l_{i j}^{y_{f}}\right\}\right)}{\left(y_{f}-y_{i}\right)}\right] \leq x_{i j}\left[\frac{\left(\sum_{y_{i}}^{y_{f}} \max \left\{u_{i j}^{y_{i}}, \ldots, u_{i j}^{y_{f}}\right\}\right)}{\left(y_{f}-y_{i}\right)}\right] \geq x_{i j}, \quad 0 \leq x_{i j} \text {, }
\end{aligned}
$$


where the lower limit score " $l_{i j}$ " and the upper limit score " $u_{i j}$ " notations are used. $x_{i j}$ is the competitiveness parameter type ( $j: E T, L, T M S, G, F) \cdot y_{i}$ (the first year of data use) and $y_{f}$ (the last year of data use) are symbolizations that indicate which data match the function.

\section{Results of Optimization Models by Statistical Analysis for UCI}

The calculation of the UCI is based on the data of the GDP and GDPPC of the countries they are affiliated with. This is because taking the factors that affect the power of UCI on a country basis has a more accurate result. The results of statistical analysis for UCI indicate that the determination of factors and responses is consistent in the general sense. Some changes and arrangements have been made on the writing of the article. The Minitab statistical analysis program was used for analysis of variance test of data in this research.

According to Table 2, it is understood that all the factors are effective on the UGDP and these factors are meaningfully significant. In addition, the significance values of the factors are considered to be effective on UGDP-PC. From these factors, only the effect of the ET and FS is less pronounced.

Firstly, Figure 1 shows how the UGDP-PC is affected by the factors. It is stated that the education factor is a constant effect and that the increase of product productivity especially affects the negative direction. The line consisting of grey points shows the average values of UGDP-PC and UGDP in Figures 1 and 2.

Figure 2 shows how the UGDP is affected by the parameters. As the scores of education, employment, and financial factors increase after a certain point, the UGDP tends to be negative. It is observed that the level of economy, the size of the market, and the productivity of the product increased the level of economy of the urban area.

In order to have the competitiveness power of the cities, the factors must have optimum values as in Figure 3. In this figure, which gives the optimum values, it is assumed that the parabolic impression of the curves belonging to the factors has more than one objective function. In such cases, improved optimization models are also defined as multiobjective optimization models. The reason for the parabolic view is that if one factor takes the maximum value for one objective function, the other has the minimum value for the objective function. In this case, it is difficult for the desirability value to be achieved at the optimum level. In addition, the optimization models established in this study show that the curves are stochastic as being parabolic. The reason for being stochastic is that the next step is unknown (steady state). A stochastic model was observed on the graph, and the parabola was observed.

According to the optimization models, the best results for the UGDP and UGDP-PC are given in Table 3. The grey area shown in Figure 3 varies with the values taken by the factors. It shows the values that can be taken in the feasible set or area of objective functions of decreasing or increasing this field. The grey regions represent the settings in which the corresponding response variable has a low value or even zero desirability. More feasible space (white region) was formed for the UGDP value, while the grey area in GDPPC was higher. The upper
TABLE 2: The analysis of variance test for UGDP and UGDP-PC.

\begin{tabular}{|c|c|c|c|c|c|}
\hline \multirow{2}{*}{ Factors } & \multirow{2}{*}{$\begin{array}{l}\text { Sample } \\
\text { size }\end{array}$} & \multicolumn{2}{|c|}{ UGDP } & \multicolumn{2}{|c|}{ UGDP-PC } \\
\hline & & Prob. & Status & Prob. & Status \\
\hline ET & 30.0 & $0.011^{*}$ & $\begin{array}{c}\text { Sig. } \\
(p<0.05)\end{array}$ & 0.995 & Not sig. \\
\hline $\mathrm{L}$ & 30.0 & $0.003^{* *}$ & $\begin{array}{c}\text { Sig. } \\
(p<0.01)\end{array}$ & $0.007^{* *}$ & $\begin{array}{c}\text { Sig. } \\
(p<0.01)\end{array}$ \\
\hline $\mathrm{T}$ & 29.0 & $0.001^{* *}$ & $\begin{array}{c}\text { Sig. } \\
(p<0.01)\end{array}$ & $0.000^{* *}$ & $\begin{array}{c}\text { Sig. } \\
(p<0.01)\end{array}$ \\
\hline MS & 30.0 & $0.049^{*}$ & $\begin{array}{c}\text { Sig. } \\
(p<0.05)\end{array}$ & $0.015^{*}$ & $\begin{array}{c}\text { Sig. } \\
(p<0.05)\end{array}$ \\
\hline G & 30.0 & $0.010^{*}$ & $\begin{array}{c}\text { Sig. } \\
(p<0.05)\end{array}$ & $0.002^{* *}$ & $\begin{array}{c}\text { Sig. } \\
(p<0.01)\end{array}$ \\
\hline $\mathrm{F}$ & 28.0 & $0.000^{* *}$ & $\begin{array}{c}\text { Sig. } \\
(p<0.01)\end{array}$ & 0.397 & Not sig. \\
\hline
\end{tabular}

Note. ${ }^{* *} p<0.01$ and ${ }^{*} p$ value $<0.05$ are significant factors, respectively; otherwise insignificant.

and lower limits of the grey areas depend on the lower and upper limits of the constraints. In the direction of optimum results, the UCI power will increase only if the urban average UGDP-PC is less than $\$ 50,523.50$ and the size of the UGDP is over $\$ 419$ million. These results reveal an urban area needs to approach these values to compete with other urban areas in economic and social areas.

Considering the optimum values of the data, new competitiveness indexes of the cities are established as shown in Table 4. The components of urban structure with the econophysics approach index (EI) are clearly observed, applied in the emerging UCI research which affects the UCI, especially the human factor. The indexes calculated by statistical physics approach of econophysics for each urban were compared with 3 different sources. $\mathrm{PwC}$ indexes considered the economic structures of cities, while UNHabitat data have considered both the economic structure and sustainable development of cities. In the study conducted for UN-Habitat, indexes have been formed in two different areas considering the economic dimensions and sustainable developments of cities. In addition to the economic dimensions of cities, biodiversity, urban mobility, technological structures, and urban planning methods which constitute the substructure of cities are considered to create indexes for cities. In our study, an index for each city was created by combining both fields in one area.

According to the comparison made with UCI, it has been determined that the method we have developed has a limited variation in some cities. In cities where changes are excessive, some factors are due to low index values belonging to developing countries. In general, the best results within the scope of UCI are spotted in cities, for example, in Europe, Far East Countries, and the United States, in terms of attractiveness for investment. As expected, top seats are occupied by "global cities," Tokyo, Madrid, Paris, Osaka, London, Seoul, and New York. These cities are major economic centres and also have significant economic leadership positions around the world. Tokyo, New York, Los Angeles, London, Osaka, Paris, Washington DC, Seoul, Madrid, and Philadelphia are among the top 10 cities. This 

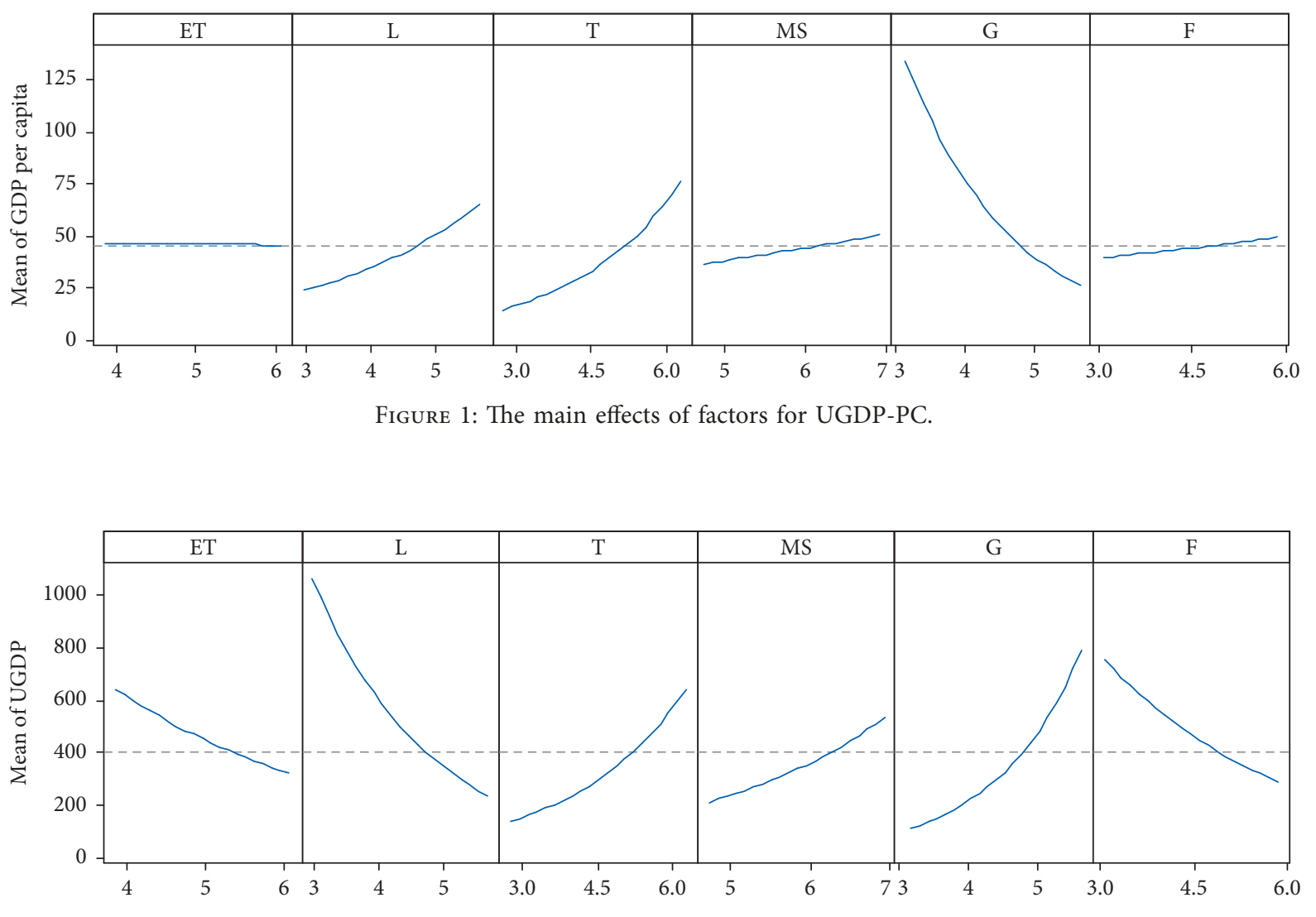

FIgUre 2: The main effects of factors for UGDP.

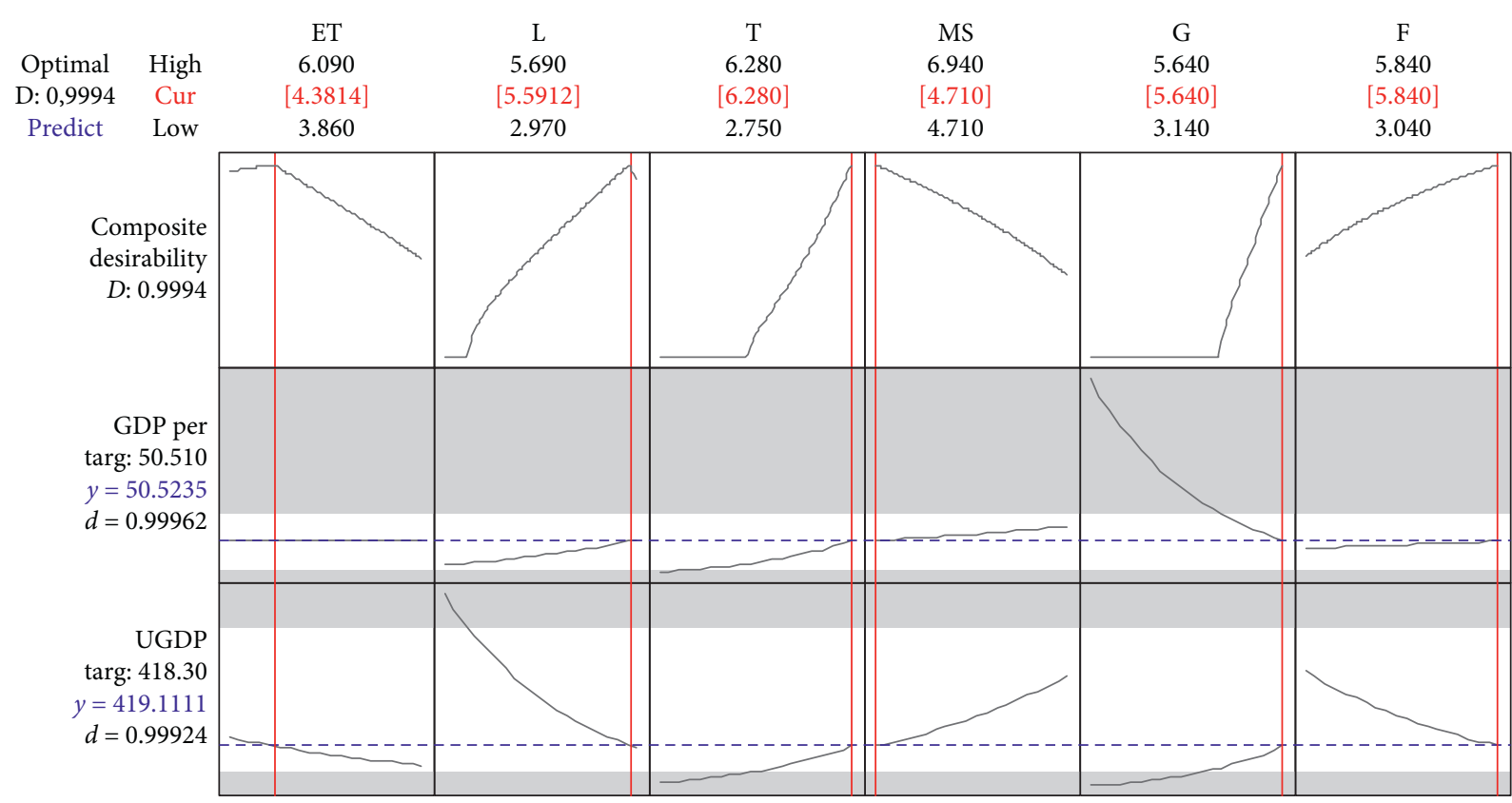

FIgURE 3: The optimum values of both response variables.

indicates the potential for being economically strong, attractive, and competitive cities for international investment. In terms of having the index of competitiveness power, the city of Buenos Aires has the lowest competitiveness, while the city with the highest competitiveness power was defined as Paris. 
TABle 3: Optimum values of factors and response variables.

\begin{tabular}{lccccccc}
\hline ET & L & T & MS & G & F & UGDP-PC & UGDP \\
\hline 4.381 & 5.591 & 6.28 & 4.71 & 5.64 & 5.84 & 50.235 & 419.111
\end{tabular}

TABLE 4: Comparisons of ranking of UCI.

\begin{tabular}{|c|c|c|c|c|c|}
\hline Urban & UCI & $\mathrm{PwC}$ & $\begin{array}{c}{ }^{*} \mathrm{UN}- \\
\text { Habitat }\end{array}$ & $\begin{array}{l}{ }^{* *} \mathrm{UN}- \\
\text { Habitat }\end{array}$ & EI \\
\hline Tokyo & 7.8353 & 1 & 7 & 3 & 3 \\
\hline New York & 6.5580 & 2 & 1 & 1 & 7 \\
\hline Los Angeles & 6.5569 & 3 & 2 & 14 & 9 \\
\hline Chicago & 6.5565 & 4 & 15 & 9 & 14 \\
\hline London & 7.0359 & 5 & 4 & 2 & 5 \\
\hline Paris & 9.3289 & 6 & 18 & 8 & 1 \\
\hline Osaka & 7.8352 & 7 & 9 & - & 4 \\
\hline Mexico City & 3.4330 & 8 & 29 & 26 & 27 \\
\hline Philadelphia & 6.5568 & 9 & 19 & 17 & 10 \\
\hline São Paulo & 3.4424 & 10 & 6 & - & 26 \\
\hline $\begin{array}{l}\text { Washington } \\
\text { DC }\end{array}$ & 6.5570 & 11 & 27 & 10 & 8 \\
\hline Boston & 6.5564 & 12 & 16 & 4 & 16 \\
\hline Buenos Aires & 0.9988 & 13 & 30 & 27 & 30 \\
\hline Dallas & 6.5567 & 14 & 8 & 21 & 12 \\
\hline Moscow & 4.6313 & 15 & 25 & 24 & 24 \\
\hline Hong Kong & 5.0950 & 16 & 11 & 11 & 22 \\
\hline Atlanta & 6.5566 & 17 & 23 & 16 & 13 \\
\hline San Francisco & 6.5565 & 18 & 5 & 12 & 14 \\
\hline Houston & 6.5560 & 19 & 10 & 7 & 19 \\
\hline Miami & 6.5562 & 20 & 14 & 23 & 18 \\
\hline Seoul & 6.8346 & 21 & 12 & 6 & 6 \\
\hline Toronto & 6.5271 & 22 & 22 & 15 & 20 \\
\hline Detroit & 6.5568 & 23 & 24 & 25 & 10 \\
\hline Seattle & 6.5563 & 24 & 20 & 13 & 17 \\
\hline Shanghai & 5.0944 & 25 & 13 & 18 & 23 \\
\hline Madrid & 8.3354 & 26 & 28 & 22 & 2 \\
\hline Singapore & 3.5065 & 27 & 3 & 5 & 25 \\
\hline Sydney & 6.2848 & 28 & 26 & 19 & 21 \\
\hline Mumbai & 1.9699 & 29 & 17 & - & 29 \\
\hline Istanbul & 3.0736 & 30 & 21 & 20 & 28 \\
\hline
\end{tabular}

Note. The cities considered for UN-Habitat were selected among the top 200 cities. The ranking indexes of the cities that are not on the list are written to the next city in the list of Table 4. PwC: PricewaterhouseCoopers [70]. *UNHabitat: the United Nations Human Settlements Programme, Global Urban Economic Competitiveness [71]. ${ }^{* *} \mathrm{UN}-\mathrm{Habitat}$ the United Nations Human Settlements Programme, Global Urban Sustainable Competitiveness [71]. EI: econophysics index.

\section{Conclusions and Future Research}

The statistical physics of the econophysics method was shown as an important approach for UCI in this study. This is the first time that the power of UCI has been linked to the social and economic factors with the application of statistical physics of the econophysics method. In order to establish the UCI, human, industry, and technology factors have to be taken into consideration in the economic parameters of the urban area. In this research, the level of education of people, urban technology, size of urban market, and urban economic development have been statistically evaluated. The reason for dealing with factors other than economic factors is that they are uniquely positioned to provide dynamic environments in which the cities operate. In addition, the vast urban areas of the world are sources of basic knowledge and innovation. This makes them central to the globalizing world economy. However, this globalizing context means increasing competition between cities in order to secure the limited resources available.

The fact that the factors that are considered to influence UCI are in large numbers triggers the artificial level of the methods to be developed. The main reason for the display of the city's competitive talents is that it makes it attractive for investment and capital. Most of the work done for urban regeneration is at the regional level, resulting in the weakening of the competitiveness of those cities as a result of global changes. In this work, competitive indexes of big cities in the world were created. The limitation of the factors taken into consideration is based on the previous studies. However, among these factors, the UCI was formed by ignoring the political structures of the countries, and therefore regulations and laws. But, it should be noted that the competitiveness of the countries is the effect of social and political structures.

There are differences in the results when we take into consideration the data of the UCI obtained by the new method (econophysical approach method) that we have chosen in this study according to the report of the World Economic Forum in 2014 and PricewaterhouseCoopers $(\mathrm{PwC})$ under the UC report. It is evident that the uncertainty and imbalance in the economies are less in the cities where UCI is high. At the same time, it is foreseen that with this approach, the high index of UC will be strong in future economies. At the same time, with the use of this approach, it is predicted that the future economies of the cities will be strong by having a high UC index.

Nevertheless, the fact that the UCI is low can be said to be a negative one in terms of the economy of the urban areas. As a result, social and economic factors are linked to UCI; tangible results have been obtained with the numerical data and the methods used for this research for the first time.

In the later stages of this research, an interactive statistical analysis of parametric and nonparametric factors will be performed by using the Box-Behnken technique, which is among the design of experiment methods by determining the different levels of the factors involved in this work. The reason for using this method is to show how the optimization models to be achieved are not linear and that the stochasticity and the factors influence the responses in the superficial graphs. In addition, it is aimed to enrich the optimum results obtained with the optimization mathematical models to be created with the scenarios.

\section{Data Availability}

The numerical data used to support the findings of this study have been deposited in the Global Urban Competitiveness Report 2011-2012. Also, we used World Bank urban development data sources. The numerical data used to support the findings of this study were supplied by Marmara University Scientific Research Institute under project no: FEN- 
C-DRP110618-0344 and so cannot be made freely available. Requests for access to these data should be made to $\mathrm{Mr}$. Abdulkadir Atalan, Bayburt University, Engineering Faculty, Department of Mechanical Engineering, Turkey, aatalan@bayburt.edu.tr.

\section{Conflicts of Interest}

The authors declare that they have no conflicts of interest.

\section{References}

[1] A. Bretagnolle, E. Daudé, and D. Pumain, "From theory to modelling: urban systems as complex systems," Cybergeo: Revue Européenne de Géographie/European Journal of Geography, 2006.

[2] L. Einav and J. Levin, "Economics in the age of big data," Science, vol. 346, no. 6210, Article ID 1243089, 2014.

[3] D. S. Hamermesh, "Six decades of top economics publishing: who and how?," Journal of Economic Literature, vol. 51, no. 1, pp. 162-172, 2013.

[4] C. A. Hidalgo, "Disconnected, fragmented, or united? a transdisciplinary review of network science," Applied Network Science, vol. 1, no. 1, p. 6, 2016.

[5] J. Gao, B. Jun, A. Pentland, T. Zhou, and C. A. Hidalgo, "Collective learning in China's regional economic development," 2017, http://arxiv.org/abs/1709.05392.

[6] C. A. Hidalgo and R. Hausmann, "A network view of economic development," Developing Alternatives, vol. 12, no. 1, pp. 5-10, 2008.

[7] T. Preis, H. S. Moat, and H. E. Stanley, "Quantifying trading behavior in financial markets using Google Trends," Scientific Reports, vol. 3, no. 1, p. 1684, 2013.

[8] J. Blumenstock, G. Cadamuro, and R. On, "Predicting poverty and wealth from mobile phone metadata," Science, vol. 350, no. 6264, pp. 1073-1076, 2015.

[9] N. Jean, M. Burke, M. Xie, W. M. Davis, D. B. Lobell, and S. Ermon, "Combining satellite imagery and machine learning to predict poverty," Science, vol. 353, no. 6301, pp. 790-794, 2016.

[10] D. Hartmann, M. R. Guevara, C. Jara-Figueroa, M. Aristarán, and C. A. Hidalgo, "Linking economic complexity, institutions, and income inequality," World Development, vol. 93, pp. 75-93, 2017.

[11] P. Salesses, K. Schechtner, and C. A. Hidalgo, "The collaborative image of the city: mapping the inequality of urban perception," PLoS One, vol. 8, no. 7, Article ID e68400, 2013.

[12] A. Llorente, M. Garcia-Herranz, M. Cebrian, and E. Moro, "Social media fingerprints of unemployment," PLoS One, vol. 10, no. 5, Article ID e0128692, 2015.

[13] J. Yuan, Q.-M. Zhang, J. Gao et al., "Promotion and resignation in employee networks," Physica A: Statistical Mechanics and Its Applications, vol. 444, pp. 442-447, 2016.

[14] C. A. Hidalgo, B. Klinger, A.-L. Barabasi, and R. Hausmann, "The product space conditions the development of nations," Science, vol. 317, no. 5837, pp. 482-487, 2007.

[15] R. Hausmann, C. A. Hidalgo, S. Bustos, M. Coscia, A. Simoes, and M. A. Yildirim, The Atlas of Economic Complexity: Mapping Paths to Prosperity, MIT Press, Cambridge, MA, USA, 2014.

[16] C. A. Hidalgo and R. Hausmann, "The building blocks of economic complexity," Proceedings of the National Academy of Sciences, vol. 106, no. 26, pp. 10570-10575, 2009.
[17] M. Cristelli, A. Gabrielli, A. Tacchella, G. Caldarelli, and L. Pietronero, "Measuring the intangibles: a metrics for the economic complexity of countries and products," PLoS One, vol. 8, no. 8, Article ID e70726, 2013.

[18] M. Cristelli, A. Tacchella, and L. Pietronero, "The heterogeneous dynamics of economic complexity," PLoS One, vol. 10, no. 2, Article ID e0117174, 2015.

[19] J. Gao and T. Zhou, "Quantifying China's regional economic complexity," Physica A: Statistical Mechanics and Its Applications, vol. 492, pp. 1591-1603, 2018.

[20] A. Chakraborti, I. M. Toke, M. Patriarca, and F. Abergel, "Econophysics review: I. Empirical facts," Quantitative Finance, vol. 11, no. 7, pp. 991-1012, 2011.

[21] R. N. Mantegna and H. E. Stanley, An Introduction to Econophysics: Correlations and Complexity in Finance, Cambridge University Press, Cambridge, UK, 2016.

[22] D. C. Montgomery, C. L. Jennings, and M. Kulahci, Introduction to Time Series Analysis and Forecasting, John Wiley \& Sons, Hoboken, NJ, USA, 2015.

[23] B. W. Silverman, Density Estimation for Statistics and Data Analysis, Routledge, Abingdon, UK, 2018.

[24] B. Jun, A. Alshamsi, J. Gao, and C. A. Hidalgo, "Relatedness, knowledge diffusion, and the evolution of bilateral trade," 2017, http://arxiv.org/abs/1709.05392.

[25] J.-P. Huang, "Experimental econophysics: complexity, selforganization, and emergent properties," Physics Reports, vol. 564, pp. 1-7, 2015.

[26] V. Plerou, P. Gopikrishnan, B. Rosenow, L. A. N. Amaral, and H. E. Stanley, "Econophysics: financial time series from a statistical physics point of view," Physica A: Statistical Mechanics and Its Applications, vol. 279, no. 1-4, pp. 443-456, 2000.

[27] S. Sinha, A. Chatterjee, A. Chakraborti, and B. K. Chakrabarti, Econophysics: An Introduction, John Wiley \& Sons, Hoboken, NJ, USA, 2010.

[28] N. Smith, "New globalism, new urbanism: gentrification as global urban strategy," Antipode, vol. 34, no. 3, pp. 427-450, 2002.

[29] M. Cimoli and J. Katz, "Structural reforms, technological gaps and economic development: a Latin American perspective," Industrial and Corporate Change, vol. 12, no. 2, pp. 387-411, 2003.

[30] P. R. Dickson, "Toward a general theory of competitive rationality," Journal of Marketing, vol. 56, no. 1, pp. 69-83, 1992.

[31] S. Szymanski, "The economic design of sporting contests," Journal of Economic Literature, vol. 41, no. 4, pp. 1137-1187, 2003.

[32] L. Nowzohour and L. Stracca, More Than a Feeling: Confidence, Uncertainty and Macroeconomic Fluctuations, European Central Bank, Frankfurt, Germany, 2017.

[33] S. Adzic and O. Sedlak, "Economic modelling and theory of fuzzy sets application in macroeconomic planning within the process of transition," Yugoslav Journal of Operations Research, vol. 8, no. 2, pp. 331-342, 1998.

[34] H. E. Stanley, L. A. N. Amaral, D. Canning, P. Gopikrishnan, Y. Lee, and Y. Liu, "Econophysics: can physicists contribute to the science of economics?," Physica A: Statistical Mechanics and Its Applications, vol. 269, no. 1, pp. 156-169, 1999.

[35] M. Gallegati, S. Keen, T. Lux, and P. Ormerod, "Worrying trends in econophysics," Physica A: Statistical Mechanics and Its Applications, vol. 370, no. 1, pp. 1-6, 2006.

[36] M. Kravchenko, "Structural balance as a basis of the economic sustainability of an enterprise," World Scientific News, vol. 57, no. 6, pp. 300-308, 2016. 
[37] A. Tacchella, M. Cristelli, G. Caldarelli, A. Gabrielli, and L. Pietronero, "A new metrics for countries' fitness and products' complexity," Scientific Reports, vol. 2, p. 723, 2012.

[38] G. Caldarelli, M. Cristelli, A. Gabrielli, L. Pietronero, A. Scala, and A. Tacchella, "A network analysis of countries' export flows: firm grounds for the building blocks of the economy," PLoS One, vol. 7, no. 10, Article ID e47278, 2012.

[39] Q. Mao, K. Zhang, W. Yan, and C. Cheng, "Forecasting the incidence of tuberculosis in China using the seasonal autoregressive integrated moving average (SARIMA) model," Journal of Infection and Public Health, vol. 11, no. 5, pp. 707-712, 2018.

[40] M. S. Mariani, A. Vidmer, M. Medo, and Y.-C. Zhang, "Measuring economic complexity of countries and products: which metric to use?," The European Physical Journal B, vol. 88, no. 11, p. 293, 2015.

[41] B. Mandelbrot, "The variation of some other speculative prices," The Journal of Business, vol. 40, no. 4, pp. 393-413, 1967.

[42] V. P. Maslov, "Econophysics and quantum statistics," Mathematical Notes, vol. 72, no. 5-6, pp. 811-818, 2002.

[43] C. Schinckus, "Economic uncertainty and econophysics," Physica A: Statistical Mechanics and Its Applications, vol. 388, no. 20, pp. 4415-4423, 2009.

[44] N. Eagle, M. Macy, and R. Claxton, "Network diversity and economic development," Science, vol. 328, no. 5981, pp. 1029-1031, 2010.

[45] J.-H. Liu, J. Wang, J. Shao, and T. Zhou, "Online social activity reflects economic status," Physica A: Statistical Mechanics and Its Applications, vol. 457, pp. 581-589, 2016.

[46] S. Singhal, S. McGreal, and J. Berry, "An evaluative model for city competitiveness: application to UK cities," Land Use Policy, vol. 30, no. 1, pp. 214-222, 2013.

[47] T. A. Hutton, "Trajectories of the new economy: regeneration and dislocation in the inner city," Urban Studies, vol. 46, no. 56, pp. 987-1001, 2009.

[48] S. Puissant and C. Lacour, "Mid-sized French cities and their niche competitiveness," Cities, vol. 28, no. 5, pp. 433-443, 2011.

[49] J. Abdullah, "City competitiveness and urban sprawl: their implications to socio-economic and cultural life in Malaysian cities," Procedia-Social and Behavioral Sciences, vol. 50, pp. 20-29, 2012.

[50] L. Sáez and I. Periáñez, "Benchmarking urban competitiveness in Europe to attract investment," Cities, vol. 48, pp. 76-85, 2015.

[51] M. Lu and Z. Chen, "Urbanization, urban-biased policies, and urban-rural inequality in China, 1987-2001," The Chinese Economy, vol. 39, no. 3, pp. 42-63, 2006.

[52] L. Salvati and P. Serra, "Estimating rapidity of change in complex urban systems: a multidimensional, local-scale Approach," Geographical Analysis, vol. 48, no. 2, pp. 132-156, 2016.

[53] P. Annoni, L. Dijkstra, and N. Gargano, EU Regional Competitiveness Index 2016, Italy, 2017.

[54] R. Huggins and N. Clifton, "Competitiveness, creativity, and place-based development," Environment and Planning A: Economy and Space, vol. 43, no. 6, pp. 1341-1362, 2011.

[55] N. Pengfei and H. Qinghu, "Comparative research on the urban competitiveness," Chinese Academy for Social Science, 2017.

[56] J. Shen, "Cross-border urban governance in Hong Kong: the role of state in a globalizing city-region," Professional Geographer, vol. 56, no. 4, pp. 530-543, 2004.
[57] N. Pengfei and P. K. Kresl, Global Urban Competitiveness Report (2011-2012), Edward Elgar Publishing, Cheltenham, UK, 2014.

[58] N. Pengfei and H. Qinghu, Comparative Research on the Global Urban Competitiveness, 2018.

[59] E. D. Viorica, Urban Competitiveness Assessment in Developing Country Urban Regions: The Rod Forward, The World Bank, Washington, DC, USA, 2000.

[60] Klaus Schwab, “The global competitiveness report 2018," World Economic Forum Reports 2018, http://www3.weforum.org/ docs/GCR2018/05FullReport/TheGlobalCompetitivenessReport 2018.pdf.

[61] N. Pengfei, M. Kamiya, R. Ding, M. Kamiya, and R. Ding, "Global urban competitiveness: comparative analysis from different perspectives," in Cities Network along the Silk Road, pp. 51-64, Springer, Singapore, 2017a.

[62] J. Bruneckiene, A. Guzavicius, and R. Cincikaite, "Measurement of urban competitiveness in Lithuania," Engineering Economics, vol. 21, no. 5, pp. 493-508, 2010.

[63] P. Kresl and B. Singh, "Urban competitiveness and US metropolitan centres," Urban Studies, vol. 49, no. 2, pp. 239-254, 2012.

[64] S. Iyer, M. Kitson, and B. Toh, "Social capital, economic growth and regional development," Regional Studies, vol. 39, no. 8, pp. 1015-1040, 2005.

[65] Z. Yuan, X. Zheng, L. Zhang, and G. Zhao, "Urban competitiveness measurement of Chinese cities based on a structural equation model," Sustainability, vol. 9, no. 4, p. 666, 2017.

[66] F.-C. Wu, "Optimization of correlated multiple quality characteristics using desirability function," Quality Engineering, vol. 17, no. 1, pp. 119-126, 2004.

[67] N. R. Costa, J. Lourenço, and Z. L. Pereira, "Desirability function approach: a review and performance evaluation in adverse conditions," Chemometrics and Intelligent Laboratory Systems, vol. 107, no. 2, pp. 234-244, 2011.

[68] Z. Hu, M. Cai, and H.-H. Liang, "Desirability function approach for the optimization of microwave-assisted extraction of saikosaponins from Radix Bupleuri," Separation and Purification Technology, vol. 61, no. 3, pp. 266-275, 2008.

[69] B. John, "Application of desirability function for optimizing the performance characteristics of carbonitrided bushes," International Journal of Industrial Engineering Computations, vol. 4, no. 3, pp. 305-314, 2013.

[70] PricewaterhouseCoopers, "Which are the largest city economies in the world and how might this change by 2025?" 2009.

[71] N. Pengfei, M. Kamiya, and W. Haibo, "The global urban competitiveness report 2017-2018-housing prices: changing world cities," 2017, https://unhabitat.org/global-urbancompetitiveness-report-2017-2018-launched/. 


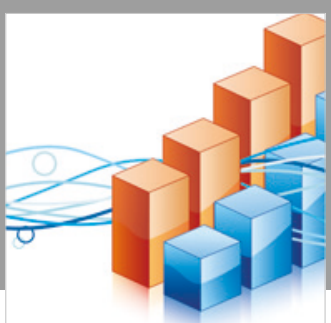

Advances in

Operations Research

\section{-n-m}
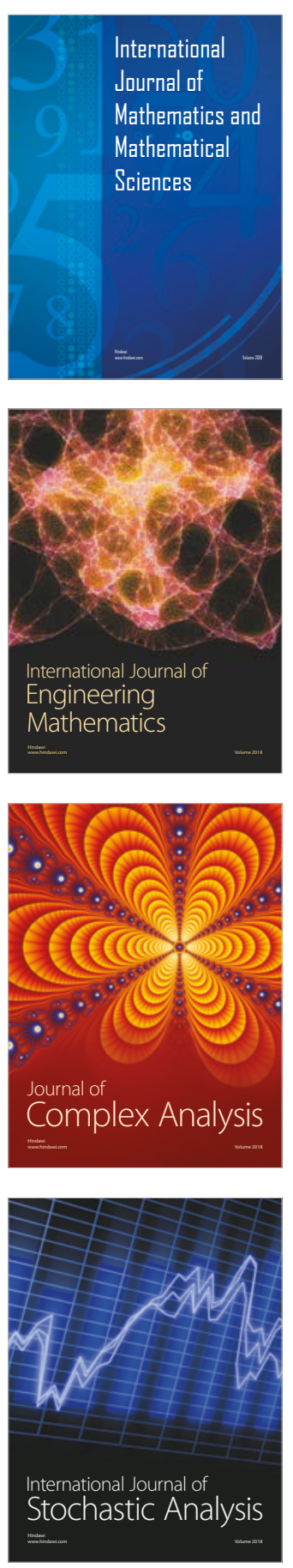
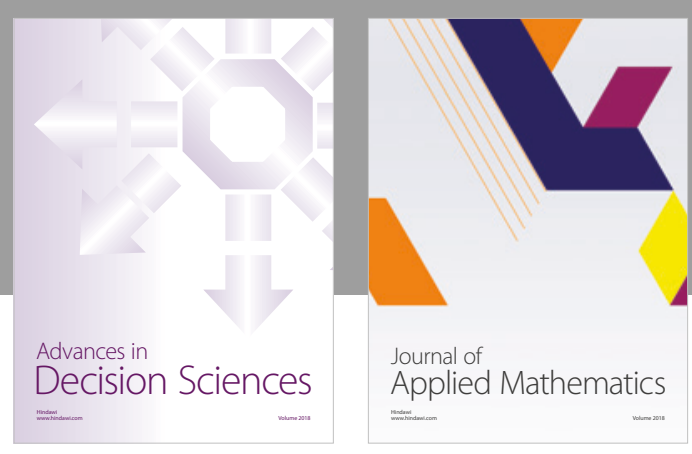

Journal of

Applied Mathematics
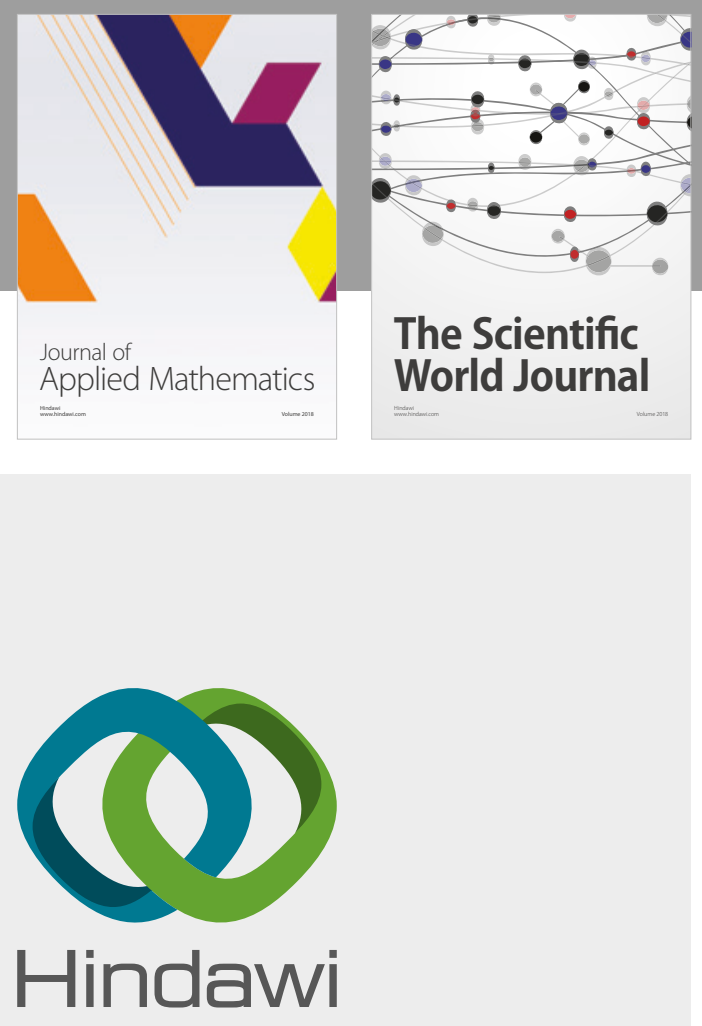

Submit your manuscripts at

www.hindawi.com

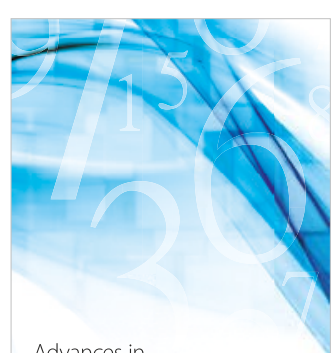

Advances in
Numerical Analysis
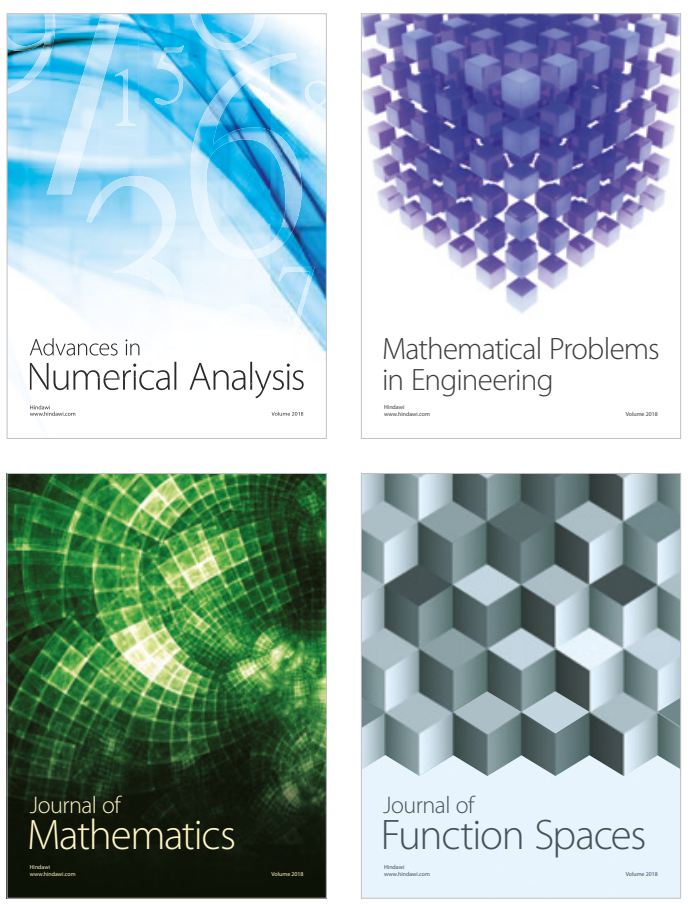

Mathematical Problems in Engineering

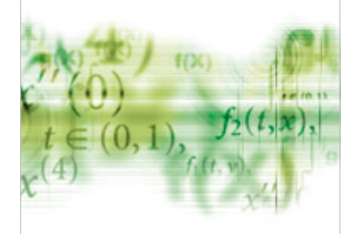

International Journal of

Differential Equations

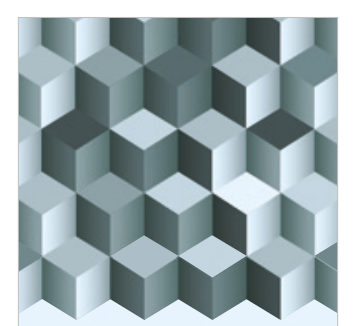

Journal of

Function Spaces
The Scientific

World Journal

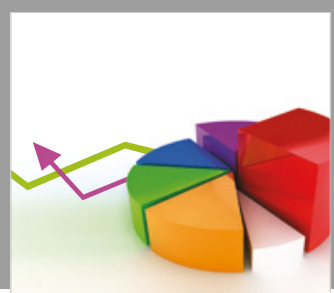

Journal of

Probability and Statistics
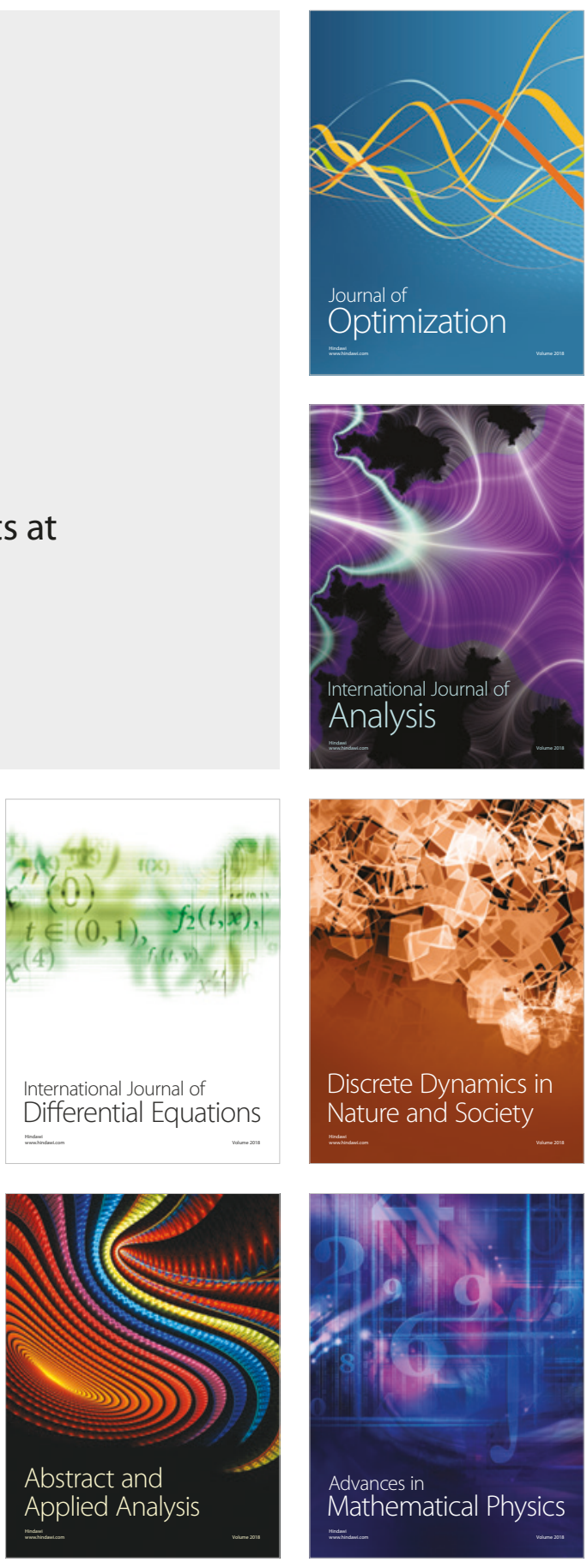